\title{
Early Maintenance of Hippocampal Mossy Fiber-Long-Term Potentiation Depends on Protein and RNA Synthesis and Presynaptic Granule Cell Integrity
}

\author{
Eduardo Calixto, Edda Thiels, Eric Klann, and Germán Barrionuevo \\ Department of Neuroscience and Center for the Neural Basis of Cognition, University of Pittsburgh, Pittsburgh, Pennsylvania 15260
}

\begin{abstract}
The neural substrates of memory likely include long-term potentiation (LTP) of synaptic strength that results from high-frequency stimulation (HFS) of the afferent pathway. The mechanisms that underlie the maintenance of LTP include RNA and protein synthesis, although the contribution of these molecular events typically does not become essential until several hours after LTP induction. We here show that, different from this pattern, (1) LTP maintenance at the mossy fiber (MF) input to CA3 pyramidal cells in the hippocampus depends on protein and RNA synthesis soon after LTP induction, and (2) some of these molecular events are controlled by signaling from the presynaptic granule cell soma. Bath application of the protein synthesis inhibitor emetine or cycloheximide $1 \mathrm{hr}$ after MF LTP induction in hippocampal slices caused loss of MF potentiation. In contrast, application of emetine $1 \mathrm{hr}$ after LTP induction at the commissural-associational input to CA3 pyramidal cells had no effect on this form of LTP. Administration of emetine or the RNA synthesis inhibitor actinomycin-D before delivery of HFS to MF input also caused a rapid decay of MF potentiation, although neither drug had an effect on the amplitude or the time-constant of decay of post-tetanic potentiation (PTP). Similarly, transection of MF axons near granule cell somas had no effect on baseline or PTP parameters but caused loss of potentiation at a rate comparable with that after actinomycin-D application. These results indicate that the mechanisms that underlie MF LTP maintenance differ from those involved in LTP maintenance at other glutamatergic synapses.
\end{abstract}

Key words: mossy fiber; LTP; CA3; dentate gyrus; protein synthesis; RNA synthesis

\section{Introduction}

Long-term potentiation (LTP) refers to a lasting increase in the amplitude of a synaptic response after high-frequency stimulation (HFS) of the presynaptic elements. Maintenance of LTP involves a series of mechanisms, with post-translational events typically underlying the early maintenance phase, and transcription- and translation-dependent events underlying the late ( $>3 \mathrm{hr}$ ) maintenance phase (Huang et al., 1994; Huang and Kandel, 1996; Bennet, 2000; Lüscher et al., 2000). Although this division into an early and a late phase of LTP maintenance on the basis of underlying intracellular mechanisms appears to apply well to LTP at the Schaeffer collateral/commissural input to area CA1 pyramidal cells (Frey et al., 1988; Nguyen et al., 1994) and the perforant path input to the dentate granule cells in the hippocampus (Krug et al., 1984; Otani et al., 1989), its applicability to LTP at the mossy fiber (MF) input to area CA3 pyramidal cells (MF LTP) is less clear.

MF LTP differs from Schaeffer collateral/commissural LTP in area CA1 in several respects, most notably in its lack of dependence on NMDA receptor activation for its induction (Harris and Cotman, 1986) and an apparently strong dependence on presynaptic mechanisms for its maintenance and expression (Xiang et

Received Dec. 10, 2002; revised March 10, 2003; accepted March 31, 2003.

This work was supported by National Institute of Neurological Disorders and Stroke Grant NS 24288 to G.B.

Correspondence should be addressed to Germán Barrionuevo, Department of Neuroscience, 441 Crawford Hall, University of Pittsburgh, Pittsburgh, PA 15260. E-mail: german@bns.pitt.edu.

Copyright $\odot 2003$ Society for Neuroscience $\quad$ 0270-6474/03/234842-08\$15.00/0 al., 1994; Weisskopf and Nicoll, 1995; Maeda et al., 1997; LopezGarcia, 1998). Although some investigators found that the early maintenance of MF LTP does not require protein synthesis (Huang et al., 1994; Huang and Kandel, 1996), other investigators showed that both the induction and the early maintenance of MF LTP are blocked by protein synthesis inhibitors (BareaRodríguez et al., 2000). The findings from this latter study, however, do not allow distinction between an effect of the inhibitors on MF LTP induction versus early maintenance, thus leaving it an open question whether the early maintenance phase of MF LTP, once it has been induced, involves the synthesis of proteins and RNA.

To address this unresolved issue of whether the early maintenance phase of MF LTP depends on protein and/or RNA synthesis, we applied either protein or RNA synthesis inhibitors either before or $1 \mathrm{hr}$ after MF LTP induction by HFS and assessed the effect on post-tetanic potentiation (PTP), a transient form of synaptic plasticity, as well as the maintenance of LTP after PTP subsided. To determine whether signals from presynaptic granule cell bodies are required for the early maintenance of MF LTP, we transected the MF axons near the cell bodies of granule cells and assessed the effect on PTP and LTP maintenance. Although baseline responses and PTP were unaffected by these manipulations, MF LTP failed to be maintained much beyond 15-30 min after its induction when these manipulations were applied before HFS. MF LTP also declined rapidly when drug was applied $1 \mathrm{hr}$ after LTP induction. Collectively, these findings indicate that the mechanisms that underlie the maintenance of MF LTP involve the synthesis of new RNA as well as proteins and that at least some 
of these molecular events appear to be implemented in the presynaptic elements of the MF-CA3 synapse.

\section{Materials and Methods}

Hippocampal slice preparation. Hippocampal slices, $450 \mu \mathrm{m}$ thick, were prepared from Sprague Dawley male rats (Zivic Miller Company; 90-120 gm) according to procedures described previously (Urban and Barrionuevo, 1996). Briefly, animals were anesthetized deeply and then perfused transcardially with cold, modified artificial CSF (ACSF) containing (in $\mathrm{mm})$ : 229 sucrose, $2.0 \mathrm{KCl}, 10$ dextrose, $26 \mathrm{NaHCO}_{3}, 1.2$ $\mathrm{Na}_{2} \mathrm{HPO}_{4} \cdot 7 \mathrm{H}_{2} \mathrm{O}$, and $1.5 \mathrm{MgCl}_{2}$, and bubbled with a mixture of $95 \% \mathrm{O}_{2} /$ $5 \% \mathrm{CO}_{2}, \mathrm{pH}=7.4$. Slices were incubated for $60 \mathrm{~min}$ at room temperature in standard ACSF containing (in $\mathrm{mM}$ ): $125 \mathrm{NaCl}, 2 \mathrm{KCl}, 10$ dextrose, 26 $\mathrm{NaHCO}_{3}, 1.2 \mathrm{Na}_{2} \mathrm{HPO}_{4} \cdot 7 \mathrm{H}_{2} \mathrm{O}, 3 \mathrm{MgCl}_{2}, 3 \mathrm{CaCl}_{2}$, and MK-801 (10-15 $\mu \mathrm{M}$ ) or D-2 amino-5-phosphonovalerate (D-APV; $25 \mu \mathrm{M}$ ) bubbled with a mixture of $95 \% \mathrm{O}_{2} / 5 \% \mathrm{CO}_{2}, \mathrm{pH}=7.4$. Slices were transferred to a recording chamber maintained at $32-33^{\circ} \mathrm{C}$ and constantly superfused $(2.5-3.0$ $\mathrm{ml} / \mathrm{min}$ ) with standard ACSF. In some experiments, MF axons were disconnected from the granule cell somas by a surgical transection through the granule cell layer of the dentate gyrus immediately after the slices were obtained. To ensure uniformity of the transection across experiments, the micro-incision was made under visual control using a dissecting microscope. Results from pilot studies showed that the amplitude of CA3 pyramidal cell responses evoked by stimulation of the MF axons recovered fully provided the slices were maintained in the incubation chamber for at least $120 \mathrm{~min}$ after the cut.

Stimulation and recording techniques. To evoke MF field EPSPs (fEPSPs), stimulation pulses were applied with bipolar electrodes placed in the granule cell layer of the dentate gyrus. In slices in which MF axons were transected, the stimulating electrodes were placed in the hilus of the dentate gyrus. To evoke commissural-associational (C/A) fEPSPs, stimulation pulses were applied to the stratum (s.) radiatum in area CA2. fEPSPs were recorded in the s. lucidum of area CA3 using glass micropipettes $(4-6 \mathrm{M} \Omega$ ) filled with $\mathrm{NaCl}$ solution $(0.5 \mathrm{M})$. Responses were displayed on an oscilloscope as well as digitalized for storage and off-line analysis (Lab View system, National Instruments, Austin TX).

Test stimuli ( $100 \mu \mathrm{sec}$ duration, $0.1 \mathrm{~Hz}$ ) were administered at a stimulation intensity $(20-70 \mu \mathrm{A})$ that elicited an fEPSP with an amplitude that was $50-60 \%$ of maximum fEPSP amplitude. The identification of MF fEPSPs was based on the following criteria: (1) negative (sink) waveform restricted to the s. lucidum; (2) short latency ( $<5 \mathrm{msec})$; (3) fast time course $(<10 \mathrm{msec})$; (4) strong paired-pulse facilitation (PPF) $(>150 \%$ at $40 \mathrm{msec}$ interstimulus interval; PPF was expressed as the amplitude ratio between the second and the first fEPSP of the pair); and (5) selective reduction by the group II metabotropic glutamate receptor agonist, $\left(2 S, 2^{\prime} R, 3^{\prime} R\right)-2-\left(2^{\prime}, 3^{\prime}\right.$-dicarboxycyclopropyl)glycine (DCG IV) $(0.5-1.0 \mu \mathrm{M})$. These criteria allowed us to distinguish MF fEPSPs from non-MF fEPSPs and from area CA3 population spikes. MF fEPSPs were monitored for at least 25-30 min (baseline period) before delivery of LTP-inducing stimulation or application of drugs. Slices that showed fluctuations in fEPSP amplitude larger than $20 \%$ were excluded from the analysis. MF LTP was induced by HFS, which consisted of 100 pulses at $100 \mathrm{~Hz}$, repeated three times at $10 \mathrm{sec}$ intervals. Changes in fEPSP amplitude were expressed as percentage of the average fEPSP amplitude recorded during the baseline period. Statistical significance of fEPSP amplitude changes was assessed by means of the paired and unpaired Student's $t$ tests. Where necessary, Bonferroni's correction factor was applied to avoid a combined $\alpha$-level that exceeded 0.05 .

All drugs were purchased from Sigma (St. Louis, MO), with the exception of cycloheximide and actinomycin-D (Calbiochem, La Jolla, CA). We used methanol $(0.1 \%)$ or ethanol $(0.4 \%)$ as vehicle solution for actinomycin-D and cycloheximide, respectively. In pilot studies we established that exposure to the vehicle solutions at those concentrations for $120 \mathrm{~min}$ had no effect on either baseline fEPSPs $(n=3)$ or the induction of MF LTP $(n=4)$.

Kinetic analysis of post-tetanic potentiation and LTP. In agreement with previous observations (Langdon et al., 1995; Urban and Barrionuevo, 1996), delivery of HFS in control experiments produced a rapid increase in MF fEPSP amplitude, named PTP. The magnitude of MF PTP was large $\left(M_{\mathrm{PTP}}=>500 \%\right)$, and first decayed rapidly (PTP time constant of decay, $\left.\tau_{\mathrm{PTP}}=<5 \mathrm{~min}\right)$ and then gradually $(<30 \mathrm{~min})$ to a stable magnitude of LTP $\left(M_{\mathrm{LTP}} \geq 160 \%\right)$, with no significant decay for the remaining duration of the experiment. To quantify the changes in peak amplitude and decay of MF fEPSPs, we fitted the time course data with two mathematical models, model A and model B (Langdon et al., 1995). The equation for model A, which predicted a stable LTP after HFS and best fit the time course data from control experiments, is as follows: $A_{\mathrm{t}}=$ $100^{*} \exp (-t / \tau) \times\left[1+M_{\mathrm{PTP}}{ }^{*} \exp \left(-t / \tau_{\mathrm{PTP}}\right)+M_{\mathrm{LTP}}\right]$.

Model B best fit the time course data from experiments in which manipulations before HFS caused changes in the magnitude and kinetics of LTP. In these cases, model B predicted that both $M_{\mathrm{PTP}}$ and $M_{\mathrm{LTP}}$ decay to baseline values with a time constant of decay $\left(\tau_{\mathrm{bsln}}\right)$. The equation for model $\mathrm{B}$ is as follows: $A_{\mathrm{t}}=100^{\star} \exp \left(-t / \tau_{\mathrm{bsln}}\right) \times\left[1+M_{\text {PTP }}{ }^{*} \exp (-t)\right.$ $\left.\left.\tau_{\text {PTP }}\right)+M_{\text {LTP }}{ }^{*} \exp \left(-t / \tau_{\text {bsln }}\right)\right]$.

Both models are plotted in Figure 3.

\section{Results}

\section{Control experiments}

Pairs of stimuli that were delivered to the cell body layer of the dentate gyrus during the baseline period evoked MF fEPSPs with a mean amplitude of $0.19 \pm 0.031 \mathrm{mV}(n=5)$ and prominent PPF $(170 \pm 50 \%)$. HFS induced robust PTP $\left(499 \pm 25 \% ; \tau_{\text {PTP }}=\right.$ $3.5 \mathrm{~min})$ that was followed by stable LTP $\left(M_{\mathrm{LTP}}=187 \pm 12 \%, 60\right.$ min after HFS) (Figs. 1A, 3; Table 1). These experiments were performed in the presence of the NMDA receptor antagonist MK-801 (10-15 $\mu \mathrm{M})$. Similar results were obtained in the presence of the NMDA receptor antagonist D-AP5 $(25 \mu \mathrm{M} ; n=4$; $M_{\text {LTP }}: 177 \pm 17 \%, 60$ min after HFS) (Table 1). Thus, the observed LTP was NMDA receptor independent and likely occurred at MF synapses.

\section{Early maintenance of MF LTP depends on protein synthesis}

To determine whether the early maintenance phase of MF LTP depends on synthesis of new proteins, we tested the effect of either one of two powerful protein synthesis inhibitors on recently established MF LTP. To that end, we first induced MF LTP and then, $60 \mathrm{~min}$ after HFS, we bath applied either emetine $(20 \mu \mathrm{M} ; n=3)$ or cycloheximide ( $60 \mu \mathrm{M} ; n=5$ ), each for $60 \mathrm{~min}$. Either inhibitor caused a marked reduction in MF fEPSP amplitude from the enhanced level observed during the first hour after HFS $\left[M_{\text {LTP }}\right.$ before emetine $=$ $176 \pm 8 \%$ (Fig. $1 B$ ); $M_{\text {LTP }}$ before cycloheximide $=169 \pm 7 \%$ (Fig. $1 C)]$. Thirty minutes after onset of either cycloheximide or emetine application, synaptic response amplitudes no longer differed significantly from baseline values [emetine: $127 \pm 13 \%$ (Fig. $1 \mathrm{~B}$ ); cycloheximide: $129 \pm 11 \%$ (Fig. $1 C$ ); $p>0.3$ ]. This decrease in fEPSP amplitude persisted for $>2 \mathrm{hr}$ after washout of emetine or cycloheximide (Fig. $1 B, C$; Table 1 ).

To determine whether protein synthesis is involved in the early maintenance of NMDA receptor-dependent LTP in area CA3 as well, we repeated the same experiment except that MK801 or D-AP5 was omitted from the perfusion bath, and LTP was induced at the commissural-associational input to CA3 pyramidal cells (C/A-LTP). In contrast to the effect of emetine on MF LTP, we found that emetine did not affect C/A-LTP. The amplitude of C/A fEPSPs at the end of 60 min of emetine application $(20 \mu \mathrm{M} ; 210 \pm 15 \% ; n=3)$ did not differ significantly from the control pre-drug level $(227 \pm 11 \%$; 60 min after HFS; $p \leq 0.1)$ (Fig. 1D; Table 1). Taken together, these findings show that in area CA3, MF LTP but not C/A-LTP requires protein synthesis within $1-2 \mathrm{hr}$ of its induction.

The foregoing results raised the question whether protein synthesis is critical to MF LTP maintenance immediately after its induction. To test this hypothesis, we bath applied emetine (20 


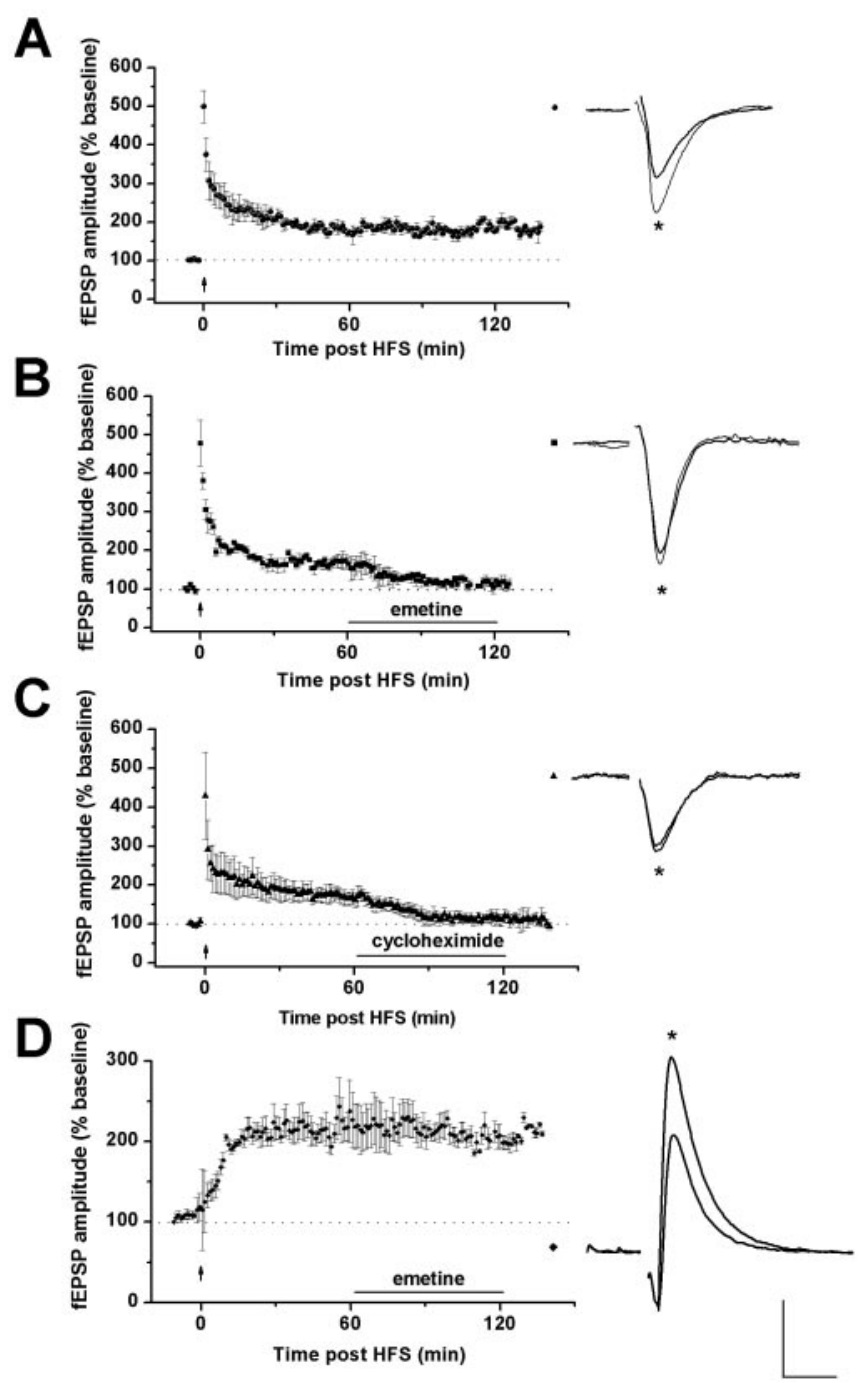

Figure 1. Inhibition of protein synthesis blocks early maintenance of MF LTP but not of C/A LTP. A, Control experiments. Left panel, Group data ( $n=5$; mean $\pm \mathrm{SEM}$; circles) of the amplitude of MF fEPSPs evoked by stimulation of MF before and after delivery of HFS (upward arrows). After PTP the amplitude of the response decayed gradually to a stable LTP. Right panel, Single traces of MF fEPSPs recorded during baseline and $120 \mathrm{~min}$ after the induction of LTP (asterisk). $B$, Left panel, Group data ( $n=3$; mean \pm SEM; squares) of the effect of emetine (20 $\mu \mathrm{M}$; applied 60 min after delivery of HFS; upward arrow) on MF LTP. Right panel, Traces are single MF fEPSPs recorded during baseline and at the end of emetine perfusion (asterisk). C, Left panel, Group data ( $n=5$; mean \pm SEM; triangles) of effect of cycloheximide ( $60 \mu \mathrm{m}$; applied 60 min after HFS; upward arrow) on MF LTP. Right traces are single MF fEPSPs recorded during baseline and at the end of cycloheximide perfusion (asterisk). Cycloheximide and emetine significantly reduced MF LTP (fEPSP amplitude before drug application vs during drug application: $p<0.01)$. All experiments were performed in the presence of MK-801 (15 $\mu \mathrm{M})$. D, Left panel, Group data of the amplitude of C/A fEPSPs evoked by stimulation of s. radiatum in area CA2. Emetine application ( $20 \mu \mathrm{m}$; rhombus; $n=3$ ) 60 min after the induction of LTP by HFS delivered to C/A fibers (upward arrow) did not affect the potentiated responses. Right panel, Representative traces of C/A fEPSPs before and at the end of emetine perfusion (asterisk). The horizontal bar indicates duration of drug perfusion ( $60 \mathrm{~min}$ ). Calibration: $0.2 \mathrm{mV}, 10 \mathrm{msec}$.

$\mu \mathrm{M})$ for $60 \mathrm{~min}$ before delivery of HFS. Emetine did not affect significantly baseline synaptic transmission (108 $\pm 3 \%$ of predrug-baseline; $n=3)$ or PPF $(179 \pm 20 \%)$. Emetine also did not affect MF-PTP $\left(M_{\mathrm{PTP}}=393 \pm 47 \% ; \tau_{\mathrm{PTP}}=2.9 \mathrm{~min}\right)$. However, after the decay of PTP, the amplitude of the fEPSP failed to remain potentiated and rapidly decreased to baseline level $\left(\tau_{\mathrm{bsln}}=\right.$ 9 min) (Figs. 2A, 3; Table 2). Within 15 min after HFS the amplitude of MF fEPSPs no longer differed significantly from base- line values $(120 \pm 13 \% ; p>0.1)$. A similarly rapid decay time constant of MF LTP $\left(\tau_{\text {bsln }}=12 \mathrm{~min}\right)$ was observed when HFS was delivered in the presence of emetine, i.e., when the $60 \mathrm{~min}$ drug application was initiated $30 \mathrm{~min}$ before delivery of HFS $(n=3$; data not shown). In these experiments, PTP amplitude and decay were comparable with these PTP parameters in control slices $\left(M_{\mathrm{PTP}}=490 \pm 52 \% ; \tau_{\mathrm{PTP}}=3.0 \mathrm{~min}\right)$, similar to the effect that we observed when emetine application was terminated before HFS. Collectively, these data show that recently established MF LTP is strongly dependent on protein synthesis.

Early maintenance of MF LTP depends on new RNA synthesis Our findings that protein synthesis is critical to the maintenance of MF LTP not long after its induction prompted us to investigate whether synthesis of a new message also plays a role in the early maintenance phase of MF LTP. To address this issue, we bath applied the RNA synthesis inhibitor actinomycin-D $(25 \mu \mathrm{M})$ for $120 \mathrm{~min}$ before delivery of HFS to MF. Actinomycin-D had no effect on basal synaptic transmission $(111 \pm 2 \%$ of pre-drug baseline; PPF $=160 \pm 12 \% ; n=4)$, PTP magnitude $\left(M_{\mathrm{PTP}}=\right.$ $531 \pm 61 \%)$, or PTP decay $\left(\tau_{\mathrm{PTP}}=2.5 \mathrm{~min}\right)$. However, the potentiation failed to persist, and MF fEPSP amplitudes returned to baseline level with a $\tau_{\text {bsln }}=33 \mathrm{~min}$ (Fig. 3; Table 2). As suggested by the greater decay time constant for these experiments compared with the rapid decay time constant observed after emetine application, MF responses were still potentiated 15 min after HFS after actinomycin-D application (170 $\pm 16 \%$; compared with baseline level; $p \leq 0.03$ ). However, within $45 \mathrm{~min}$ after HFS the amplitude of MF fEPSPs no longer differed significantly from baseline values $(125 \pm 10 \% ; p>0.1)$ (Fig. $2 B)$. In slices treated with vehicle solution (methanol), PTP and LTP were similar to those measured in control slices $\left(M_{\mathrm{PTP}}=491 \pm 39 \% ; M_{\mathrm{LTP}}=\right.$ $\left.168 \pm 19 \% ; \tau_{\mathrm{PTP}}=2.9 \mathrm{~min} ; n=3\right)$. These data show that the early maintenance phase of MF LTP requires the synthesis of RNA, in addition to the synthesis of proteins.

\section{Early maintenance of MF LTP depends on granule cell soma}

Our findings that RNA synthesis is critical for the maintenance of MF LTP not long after its induction raised the question of whether granule cell somas contribute to the early maintenance phase of MF LTP. To address this question, we transected the MF axons near the granule cell bodies $>2 \mathrm{hr}$ before HFS. Transection of MF axons had no effect on baseline MF fEPSPs monitored for $90 \mathrm{~min}$ (mean amplitude $=0.21 \pm 0.04 \mathrm{mV} ; \mathrm{PPF}=140 \pm 21 \%$; $n=5)$ or on PTP amplitude or decay $\left(M_{\mathrm{PTP}}=512 \pm 41 \%\right.$; $\tau_{\mathrm{PTP}}=3.1 \mathrm{~min} ; p>0.1$ ) (Table 2). However, in the absence of granule cell soma, the potentiated MF fEPSP decayed to baseline level with a time constant comparable with that seen after application of actinomycin-D ( $\left.\tau_{\text {bsln }}=31 \mathrm{~min}\right)$ (Fig. 3; Table 2). Thus, similar to the effect observed after HFS after actinomycin-D application, the amplitude of MF fEPSPs after MF transection was increased significantly above baseline level 15 min after HFS $(196 \pm 21 \% ; p<0.01)$, but the potentiation did not persist and MF fEPSP amplitudes returned to baseline level within $45 \mathrm{~min}$ after HFS (136 $\pm 19 \% ; p>0.1)$ (Fig. 2C). These data indicate that integrity of communication between soma and terminals of the presynaptic granule cell is necessary to maintain MF LTP soon after its induction.

Interestingly, the time course of response decay after HFS in MF transected slices (Fig. 2C) resembled that after HFS after actinomycin-D application (Fig. $2 B$ ) but was distinctly slower than that after HFS after emetine application (Fig. 2A). These findings suggest that MF transection and inhibition of RNA syn- 
Table 1. Effects of inhibition of protein synthesis after LTP induction

\begin{tabular}{|c|c|c|c|c|c|}
\hline Groups & $\begin{array}{l}\text { PTP magnitude } \\
\text { (\% baseline) }\end{array}$ & $\begin{array}{l}\tau_{\text {PTP }} \\
(\min )\end{array}$ & $\begin{array}{l}\text { fEPSP amplitude } 60 \text { min } \\
\text { after HFS (\% baseline) }\end{array}$ & $\begin{array}{l}\text { fEPSP amplitude } 120 \text { min } \\
\text { after HFS (\% baseline) }\end{array}$ & $\begin{array}{l}\tau_{\text {bsln }} \\
(\mathrm{min})\end{array}$ \\
\hline MF LTP control (MK 801; $10-15 \mu \mathrm{m} ; n=5$ ) & $499 \pm 25$ & 3.5 & $187 \pm 12$ & $179 \pm 7$ & N/A \\
\hline MF LTP control (D-APV; $25 \mu \mathrm{m} ; n=4)$ & $484 \pm 40$ & 2.6 & $177 \pm 17$ & $181 \pm 6$ & $\mathrm{~N} / \mathrm{A}$ \\
\hline Emetine (20 $\mu \mathrm{m} ; 60 \mathrm{~min} ; n=3$ ) after MF LTP induction & $490 \pm 52$ & 2.9 & $176 \pm 8$ & $114 \pm 2$ n.s. & 28 \\
\hline Cycloheximide ( $60 \mu \mathrm{m} ; 60 \mathrm{~min} ; n=3)$ after MF LTP induction & $429 \pm 50$ & 2.8 & $169 \pm 7$ & $111 \pm 7$ n.s. & 26 \\
\hline C/A-LTP control $(n=3)$ & N/A & $\mathrm{N} / \mathrm{A}$ & $227 \pm 11$ & $247 \pm 21$ & N/A \\
\hline Emetine $(20 \mu \mathrm{m} ; 60 \mathrm{~min} ; n=3)$ after C/A-LTP induction & $\mathrm{N} / \mathrm{A}$ & $\mathrm{N} / \mathrm{A}$ & $210 \pm 15$ & $217 \pm 26$ & $\mathrm{~N} / \mathrm{A}$ \\
\hline
\end{tabular}

n.s., Statistically not significantly different from baseline values; N/A, not applicable.

A

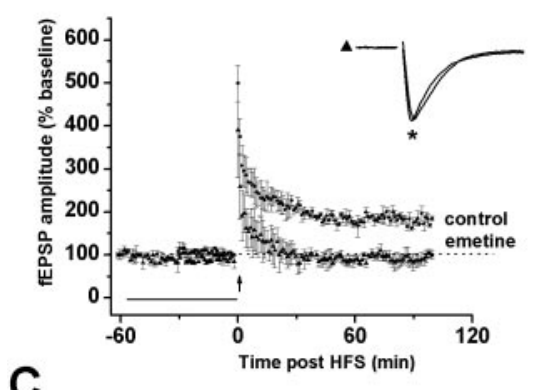

C

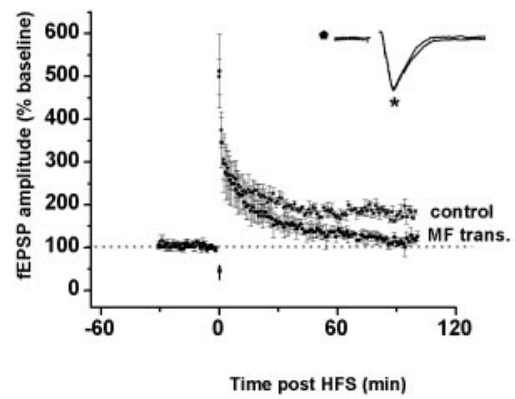

B

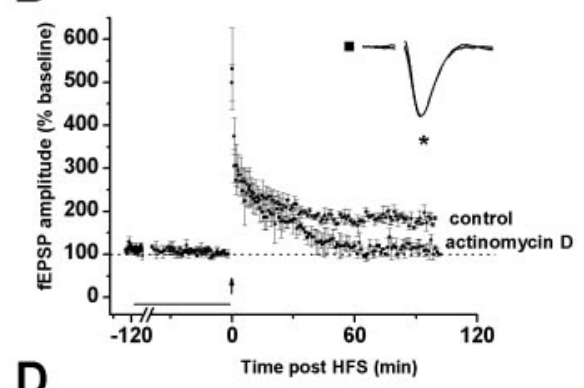

D

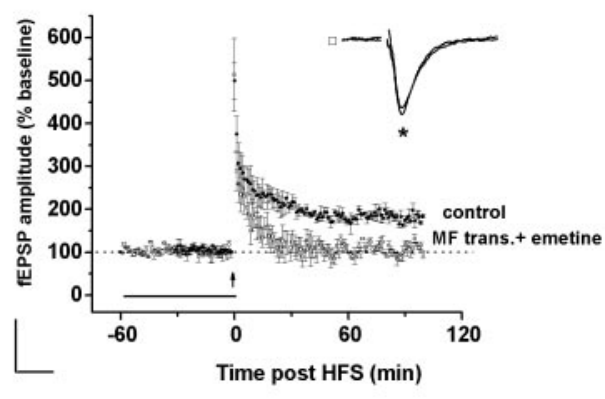

Figure 2. Early maintenance of MF LTP is blocked by inhibition of either protein or RNA synthesis as well as by MF transection. Group data (mean \pm SEM) of the amplitude of MF fEPSPs before and after HFS (upward arrow). The horizontal bar in $A, B$, and $D$ indicates the duration of drug application before HFS. $A$, Effect of emetine incubation for $60 \mathrm{~min}$ before delivery of HFS to the MF (20 $\mu \mathrm{M} ; n=3$; triangles). $B$, Effect of actinomycin-D incubation for 120 min before delivery of HFS to the MF ( $25 \mu \mathrm{m} ; n=4$; filled squares). C, Effect of MF transection performed $120 \mathrm{~min}$ before the onset of electrophysiological recordings ( $n=5$; filled pentagon). The same HFS as delivered in these experiments induced persistent MF LTP in control slices (filled circles; $n=5$ ). $D$, Joint effect of emetine incubation ( $20 \mu \mathrm{m} ; 60$ min before delivery of HFS) and MF transection on MF LTP ( $n=4$; open squares). Representative traces of MF fEPSPs were obtained 10 min before and 60 min after HFS or 90 min after delivery of HFS in slices with MF transection (asterisk). Calibration: $0.2 \mathrm{mV}, 10 \mathrm{msec}$.

thesis interfere with the same underlying process critical for MF LTP maintenance, whereas inhibition of protein synthesis acts on a different process, the contribution of which is recruited before the one that involves signaling between presynaptic soma and terminals and new RNA synthesis. If this hypothesis of distinct underlying processes is correct, then the time course of response decay after HFS after emetine application should be the same regardless of the intactness of the MF axons. To test this hypothesis, we applied emetine $(20 \mu \mathrm{M})$ for $60 \mathrm{~min}$ before delivery of HFS in slices with MF transected. Emetine had no effect on basal synaptic transmission $(109 \pm 5 \%$ of baseline; PPF $=144 \pm 11 \%$; $n=4)$ or PTP magnitude or decay $\left(M_{\mathrm{PTP}}=513 \pm 98 \% ; \tau_{\mathrm{PTP}}=\right.$ $2.8 \mathrm{~min})$. However, potentiated MF fEPSPs returned to baseline levels with a $\tau_{\text {bsln }}=10 \mathrm{~min}$ (Figs. $2 \mathrm{D}, 3$; Table 2). The decay time constant of potentiation in transected slices was similar to that observed after emetine applications in control slices (Figs. 2A, 3; Table 2). Thirty minutes after HFS, the amplitude of MF fEPSPs no longer differed significantly from baseline values $(p>0.2)$. These findings corroborate the suggestion that the protein syn- thesis inhibitor when present before and immediately after LTP-inducing HFS interferes with events unrelated to those affected by inhibition of RNA synthesis or MF transection.

PPF and PTP in slices with transected MF axons were comparable with these measures of presynaptic function in slices with intact MF axons (see above). Nevertheless, it is possible that failure of sustained MF LTP after MF transection is secondary to effects on the function of the postsynaptic CA3 pyramidal cell caused by massive release of glutamate from MF boutons during the transection. To rule out this possibility we tested slices in which the MF axons were transected in the presence of kynurenic acid, a nonselective NMDA, and AMPA/kainate receptor antagonist $(10 \mathrm{~mm} ; n=4)$. The slices were incubated in kynurenic acid for $60 \mathrm{~min}$ after MF transection. The results from kynurenic acid-treated slices were similar to those from slices in which the transection was conducted in the absence of kynurenic acid. The amplitude of MF fEPSPs during baseline was $0.40 \pm 0.1 \mathrm{mV}$ $(\mathrm{PPF}=160 \pm 32 \%) ; M_{\mathrm{PTP}}$ was $403 \pm$ $47 \%$; $\tau_{\text {PTP }}$ was $2.8 \mathrm{~min}$; and within $45 \mathrm{~min}$ after HFS, the amplitude of the MF EPSPs no longer differed significantly from baseline values ( $136 \pm 19 \%$; data not shown). These control experiments indicate that it is unlikely that a massive release of glutamate after MF transection impacted negatively on subsequent induction and/or maintenance of MF LTP.

It also is possible that the failure of MF LTP maintenance after MF transection is a consequence of a generalized effect on CA3 pyramidal cell function, including its ability to support long-term plasticity. To rule out this possibility, we tested the effect of MF transection on C/A-LTP. In three slices, we monitored both evoked C/A fEPSPs (mean amplitude $=0.22 \pm 0.06 \mathrm{mV}$ ) (Fig. 4) and evoked MF fEPSPs (mean amplitude $=0.20 \pm 0.04 \mathrm{mV}$ ). Bath application of the NMDA receptor antagonist D-APV (50 $\mu \mathrm{M})$ had no effect on evoked MF fEPSPs but caused a slight reduction in C/A fEPSPs ( $10 \pm 2 \%$ of pre-drug baseline). Delivery of HFS to the MF input induced robust PTP $\left(M_{\mathrm{PTP}}=552 \pm\right.$ $45 \% ; \tau_{\text {PTP }}=2.8 \mathrm{~min}$ ), but the potentiated response decayed to baseline levels within 27 min after HFS (Fig. 4). Thirty minutes after delivery of HFS to the MF input, we delivered a similar HFS to the C/A input. The amplitude of evoked C/A fEPSPs gradually 


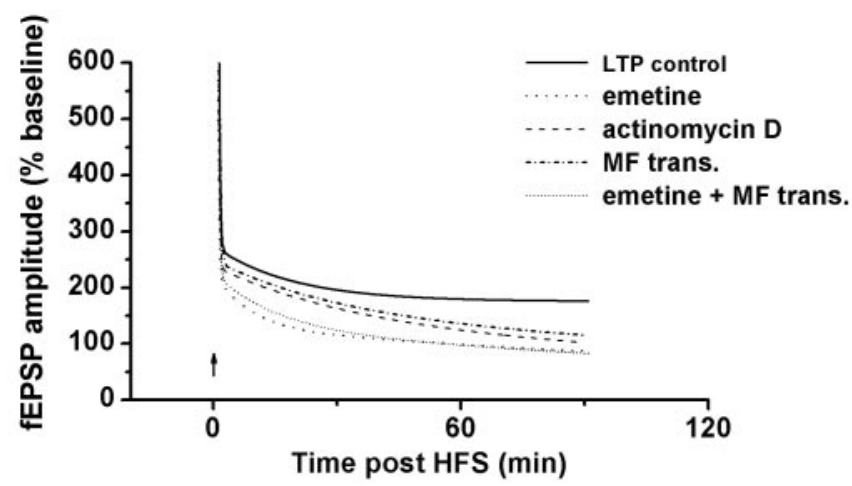

Figure 3. Time course of the decay of MF fEPSP amplitude after HFS. Curves are the mathematical best fits of data from control experiments (Fig. 1A) and the experiments shown in Figure $2 A-D$. The time course of LTP in control experiments was fit best with model $A$. In this case, PTP decayed to a nondecremental level of LTP (see Materials and Methods). Because of the application of either emetine or actinomycin-D before delivery of HFS, the decay of LTP was fit best with model B (see Materials and Methods). Model B assumes that the amplitude of both PTP and LTP decayed with different time constants back to pre-HFS amplitude values (see Materials and Methods). Upward arrow indicates the time at which HFS was delivered.

increased $(191 \pm 17 \% ; 30$ min after HFS $)$ and was similar to what we observed in the absence of transected MF (Fig. 1C). The potentiation of the C/A fEPSP was stable for $>2 \mathrm{hr}$ and unaffected by bath application of the group II mGluR agonist DCG IV ( 0.5 M; $169 \pm 12 \%$ of baseline). In contrast, DCG IV reduced MF fEPSPs below baseline level $(67 \pm 16 \%)$. This selective reduction of MF fEPSPs was reversible. Taken together, these data suggest that MF transection does not affect the ability of CA3 pyramidal cells to maintain LTP induced at a non-MF synaptic input.

\section{Forskolin-induced MF potentiation does not depend on granule cell soma but on protein synthesis}

Previously it has been suggested that presynaptic PKA activation is obligatory for the induction and maintenance of MF LTP (Huang et al., 1994; Weisskopf et al., 1994; Villacres et al., 1998). Therefore, the failure of transected slices to sustain MF LTP could be caused by alterations in the cAMP/PKA second messenger cascade in MF presynaptic boutons. To test this possibility, we examined the effects of the activator of adenylyl cyclase, forskolin $(100 \mu \mathrm{M})$, in conjunction with a nonspecific inhibitor of cAMP and/or cGMP phosphodiesterases [3-isobutyl-1-methylxantine (IBMX), $50 \mu \mathrm{M}$ ] in control slices and slices with MF transection in the presence of MK-801 (15 $\mu \mathrm{M})$. As reported previously (Huang et al., 1994; Weisskopf et al., 1994), a brief exposure to forskolin/ IBMX (20 min) produced a gradual increase in the amplitude of evoked MF fEPSPs in control slices ( $n=5$ ) (Fig. $5 A$, filled circles). The potentiation of MF fEPSPs reached stable values within 15 min after initiation of drug perfusion $(272 \pm 51 \%)$ and was maintained without decay for $90 \mathrm{~min}$. Subsequently, the amplitude of MF fEPSPs showed a gradual but not statistically significant decrease to $257 \pm 38 \%, 120 \mathrm{~min}$ after exposure to forskolin/ IBMX $(p>0.1)$. The effect of forskolin/IBMX application on slices with MF transection $(n=4)$ (Fig. $5 A$, open circles) was similar to the effects of the drugs in control slices. Within 15 min after onset of exposure to forskolin and IBMX, the amplitude of evoked MF fEPSPs exhibited a long-lasting enhancement (220 \pm $39 \% ; 15$ min after initiation of superfusion of forskolin/IBMX) that remained stable for $120 \mathrm{~min}$. Although the magnitude of the potentiation induced by forskolin/IBMX in MF transected slices tended to be slightly lower compared with the potentiation observed in control slices ( $211 \pm 34 \% ; 120 \mathrm{~min})$. This difference between the two preparations was not statistically significant 60 min after exposure to forskolin/IBMX $(p>0.4)$. These data indicate that the MF-CA3 pyramidal cell synapse after MF transection is capable of supporting lasting forskolin-induced potentiation.

Although PKA activation was found to be necessary for the induction and maintenance of MF LTP, one might raise concerns that the mechanisms underlying forskolin-induced MFpotentiation differ from those that underlie HFS-induced MF potentiation. To test whether forskolin- and HFS-induced LTP share common maintenance mechanisms, we examined the effect of the protein synthesis inhibitor emetine on forskolininduced MF potentiation. After obtaining stable baseline MF fEPSP amplitudes ( $109 \pm 4 \%$; $n=3$ ), a brief exposure to forskolin/IBMX (100 $\mu \mathrm{M} / 50 \mu \mathrm{M} ; 20 \mathrm{~min})$ produced a significant amplitude increase of evoked MF fEPSPs that reached stable values within 13 min after onset of drug perfusion ( $327 \pm 55 \%$ of baseline) (Fig. $5 B$, filled squares). Emetine ( $20 \mu \mathrm{M} ; 60 \mathrm{~min}$ ) applied 60 min after the application of forskolin/IBMX caused a marked reduction in the amplitude of MF fEPSPs relative to the amplitude recorded at the onset of emetine perfusion (316 $\pm 32 \%)$. Thirty minutes after termination of emetine perfusion, amplitude values were not significantly different from baseline levels $(117 \pm 12 \% ; p>0.3$ ) (Fig. $5 B$ ). These findings show that forskolin-induced potentiation, like HFS-induced potentiation, fails to be maintained when protein synthesis is inhibited. The results therefore support the assumption that forskolin-induced MF-potentiation taps into the same mechanisms involved in HFS-induced potentiation and thus warrant our conclusion that MF transected fibers are capable of supporting lasting MF potentiation downstream of adenylyl cyclase activation. Taken together, the results from the studies reported here make a strong case that the early maintenance phase of electrically induced MF LTP depends on intact signaling between granule cell soma and MF boutons.

\section{Discussion}

\section{Summary}

The present results reveal that the maintenance of recently established MF LTP is strongly dependent on protein and RNA synthesis. Specifically, administration of the protein synthesis inhibitors emetine or cycloheximide after MF LTP induction caused depotentiation of synaptic responses in $<30 \mathrm{~min}$ (Fig. $1 \mathrm{~B}, \mathrm{C}$ ). In contrast, administration of emetine after C/A LTP induction did not affect potentiated C/A fEPSPs (Fig. $1 D$ ). Our results also show that blockade of protein synthesis or RNA synthesis before HFS of MF causes a rapid decay of MF LTP (Figs. 2 B, 3, 4). These results are consistent with those of Barea-Rodríguez et al. (2000), who reported that anisomycin applied before HFS blocked MF LTP in vivo. However, the findings of Barea-Rodríguez et al. (2000) did not allow the investigators to dissociate an effect of the protein synthesis inhibitor on MF LTP induction from an effect of the agent on MF LTP maintenance. Our study shows unambiguously that neither emetine nor actinomycin-D blocked the induction of MF LTP (see below). Our findings also demonstrate that the early maintenance of MF LTP depends on the integrity of communication between dentate gyrus granule cell soma and the MF bouton.

\section{Early maintenance phase of MF LTP depends on protein and} RNA synthesis

Numerous studies have demonstrated that the early maintenance phase of LTP at the MF to CA3 synapse (Frey et al., 1993; Huang 
Table 2. Effects of inhibition of protein synthesis, RNA synthesis, or MF transection before LTP induction

\begin{tabular}{|c|c|c|c|c|}
\hline Groups & $\begin{array}{l}\text { PTP magnitude } \\
\text { (\% baseline) }\end{array}$ & $\begin{array}{l}\tau_{\text {PTP }} \\
\text { (min) }\end{array}$ & $\begin{array}{l}\text { fEPSP amplitude } 60 \text { min } \\
\text { after HFS (\% baseline) }\end{array}$ & $\begin{array}{l}\tau_{\text {bsln }} \\
(\mathrm{min})\end{array}$ \\
\hline MF LTP control (MK 801; $10-15 \mu \mathrm{m} ; n=5)$ & $499 \pm 25$ & 3.5 & $187 \pm 12$ & $\mathrm{~N} / \mathrm{A}$ \\
\hline MF LTP control (D-APV; $25 \mu \mathrm{m} ; n=4)$ & $484 \pm 40$ & 2.6 & $177 \pm 17$ & N/A \\
\hline Emetine (20 $\mu \mathrm{m} ; 60 \mathrm{~min} ; n=3)$ before MF LTP induction & $393 \pm 47$ & 2.9 & $101 \pm 2$ n.s. & 9 \\
\hline Actinomycin D (25 $\mu \mathrm{m} ; 120 \mathrm{~min} ; n=4)$ before MF LTP induction & $531 \pm 61$ & 2.5 & $117 \pm 4$ n.s. & 33 \\
\hline MF transection before MF LTP induction $(n=5)$ & $512 \pm 41$ & 3.1 & $130 \pm 19$ n.s. & 31 \\
\hline MF transection before C/A-LTP induction $(n=3)$ & N/A & $\mathrm{N} / \mathrm{A}$ & $208 \pm 15$ & $\mathrm{~N} / \mathrm{A}$ \\
\hline MF transection + emetine $(20 \mu \mathrm{m} ; 60 \mathrm{~min} ; n=4)$ before MF LTP induction & $513 \pm 98$ & 2.8 & $104 \pm 5$ n.s. & 10 \\
\hline
\end{tabular}

n.s., Statistically not significantly different from baseline values. Control groups are the same as shown in Table 1. N/A, Not applicable.

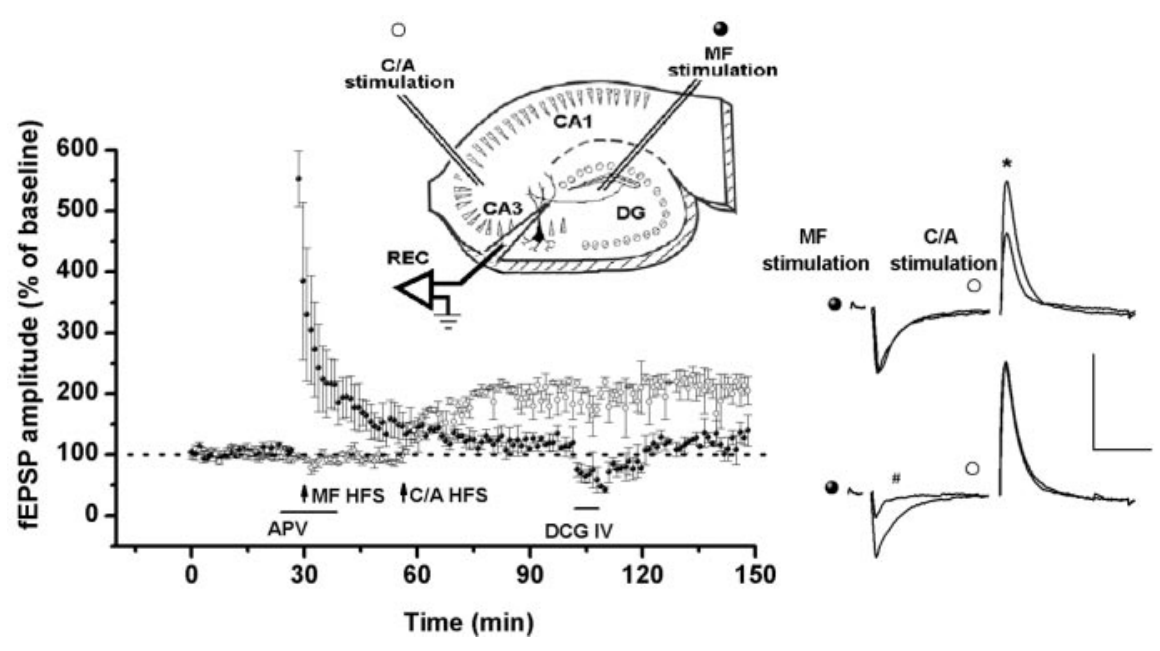

Figure 4. MF transection does not affect the ability of CA3 pyramidal cells to maintain LTP induced at a non-MF synaptic input. Left panel, MF fEPSPs were recorded in the presence of APV ( $50 \mu \mathrm{m}$ ) for 20 min before the delivery of HFS (first upward arrow). Delivery of HFS to MF induced PTP but not MF LTP (filled circles; $n=3$ ). Thirty minutes after delivery of HFS to MF, a second HFS delivered to the C/A fibers (second upward arrow) induced stable C/A LTP (open circles). In the presence of DCG IV (0.5 $\mu \mathrm{m}$ for 15 $\mathrm{min}$ ), MF fEPSPs were reduced selectively. Insert, Schematic of hippocampal slice showing the position of the stimulation and recording electrodes and the transection of MF. Right panel, Single traces of MF fEPSPs (left) and C/A fEPSPs (right). Top traces show fEPSP before and 30 min after delivery of HFS to the C/A input. Only C/A fEPSPs are potentiated (asterisk). Bottom traces show the selective depression of DCG IV on MFfEPSPs (\#). The horizontal bar indicates the duration of drug application. Calibration: $0.2 \mathrm{mV}, 10 \mathrm{msec}$.

et al., 1994; Huang and Kandel, 1996; Nguyen and Kandel, 1996) and the Schaffer collateral to CA1 synapse (Krug et al., 1984; Stanton and Sarvey, 1984; Frey et al., 1988; Huang et al., 1996; Mochida et al., 2001) is independent of protein synthesis. In contrast, other published work indicates that the early maintenance phase of LTP in area CA1 (Deadwyler et al., 1987; Clayton, 2000; Scharf et al., 2002), in the dentate gyrus (Otani and Abraham, 1989; Otani et al., 1989; Nguyen et al., 1994), and at the MF synapse (Barea-Rodríguez et al., 2000) is protein synthesis dependent. In the present study, the inhibitory effect of either emetine or actinomycin-D on the early maintenance of MF LTP cannot be attributed to a drug effect on baseline synaptic transmission or short-term plasticity. Specifically, MF fEPSP amplitudes during baseline were not affected by incubation with either emetine or actinomycin-D. In addition, the time course of amplitude changes of MF fEPSPs after HFS showed that in slices exposed to emetine or actinomycin-D before HFS, the magnitude and decay time constant of PTP were similar to control values and to values reported previously (Langdon et al., 1995; Son and Carpenter 1996). Importantly, MF responses in drug-treated slices remained potentiated well after the decay of PTP. These results indicate that blockade of protein or RNA synthesis selectively inhibited the early maintenance phase of MF LTP without affecting the induction process.
One possible site of action of emetine is the dendrite of the postsynaptic CA3 pyramidal cell. Traditionally, it has been thought that new proteins are synthesized in the cell body of the neuron and transported to the synapse. However, numerous recent studies suggest that train stimulation of afferent fibers induces local protein synthesis in dendrites of the postsynaptic cell (Aakalu et al., 2001; Job and Eberwine, 2001; Smith et al., 2001; Steward and Schuman, 2001; Steward and Worley, 2002). For example, in area CA1 the expression and insertion of AMPA receptors (Kacharmina et al., 2000; Malinow and Malenka, 2002) and the expression of cellular adhesion molecules, such as cadherins and proteins of cytoskeleton (Kim and Lisman 1999; Yamagata et al., 1999; Krucker et al., 2000), are induced in dendritic spines by high-frequency stimulation. It also was shown that the expression of CaM kinase II, a protein critical for the maintenance of LTP (Ouyang et al., 1999; Davis et al., 2000), is induced locally in the dendrites of CA3 pyramidal cells (Chicurel et al., 1993). The time course of protein synthesis in the postsynaptic cell after LTP induction appears to be rapid because new proteins appear within 15-45 min after HFS (Lynch et al., 1994; Osten et al., 1996; Lanahan and Worley, 1998; Ouyang et al., 1999). These data are consistent with the time course of decay of MF LTP in slices treated with emetine described here.

Our data also show that the mechanisms that underlie the maintenance of MF LTP are markedly different from those that underlie the maintenance of LTP at non-MF synapses. Specifically, the early phase of C/A LTP is insensitive to emetine, which indicates that it does not require the synthesis of new proteins. A similar negative effect of emetine was reported for LTP in the CA1 region (Krug et al., 1984; Nguyen et al., 1994). In addition to inducing rapid protein synthesis in dendrites, HFS also induces an increase in the expression of proteins involved in vesicular neurotransmitter release, such as synapsin I, synaptotagmin, and synaptophysin (Lynch et al., 1994; Hicks et al., 1997; Sato et al., 2000). It is therefore possible that the synthesis of RNAs and proteins necessary for the maintenance of MF LTP takes place solely in the presynaptic element (granule cell soma; see below).

Finally, the decay of MF LTP produced by emetine is consistent with a role for both presynaptic and postsynaptic cells in the induction and maintenance of MF LTP, as demonstrated recently 


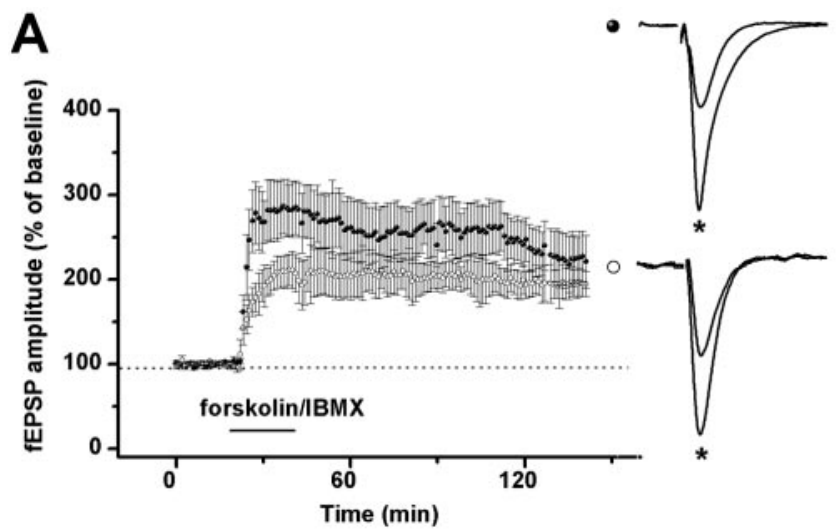

B

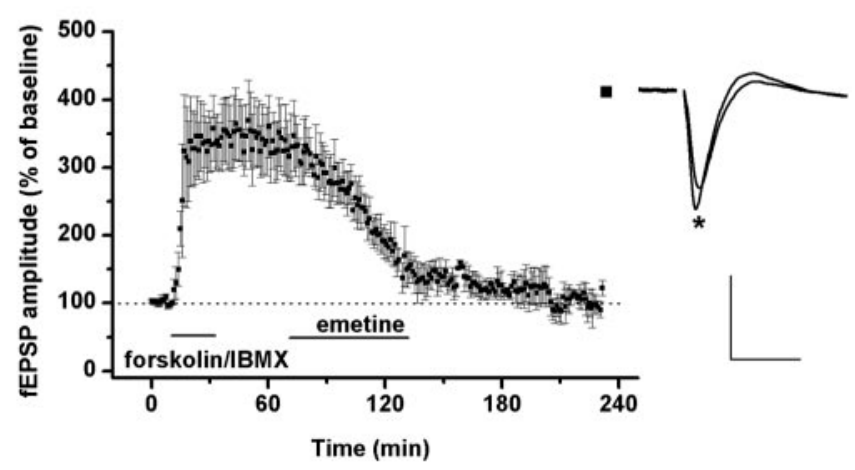

Figure 5. Forskolin induces potentiation of MF fEPSPs in control and MF transected slices that is dependent on protein synthesis. $A$, Left panel shows the time course of potentiation after transient application of forskolin $(100 \mu \mathrm{M}) / \mathrm{IBMX}(50 \mu \mathrm{m} ; 20 \mathrm{~min}$, horizontal bar; in the presence of MK 801, $15 \mu \mathrm{M}$ ) in slices with MF transection ( $n=4$; open circles) or control slices ( $n=$ 5; filled circles). MF LTP in slices with MF transection was not statistically different from MF LTP in control slices 30 min after exposure to forskolin/IBMX ( $p>0.4)$. Right panel shows examples of MF fEPSPs recorded during the baseline period and $60 \mathrm{~min}$ after forskolin/IBMX perfusion (asterisk); top traces, MF LTP in control slices; bottom traces, fEPSP from slices with MF transection. $B$, Effect of emetine incubation ( $20 \mu \mathrm{m} ; 60 \mathrm{~min}$ ) on potentiation induced by forskolin/IBMX ( $n=3$; filled squares). After emetine application, MF fEPSPs returned to baseline values. Right panel shows MF fEPSPs recorded during baseline and $60 \mathrm{~min}$ after termination of emetine incubation (asterisk). Calibration: $0.2 \mathrm{mV}, 10 \mathrm{msec}$.

by Contractor et al. (2002). These authors have identified a retrograde signaling cascade involving Eph B receptor-ephrin ligand interactions that link postsynaptic calcium influx into CA3 pyramidal cells with increased transmitter release by presynaptic MF boutons. Similar to our results with emetine, blockade of the $\mathrm{C}$ terminal of EphB2 receptors produced an early decay of MF LTP with little effect on PTP. However, in light of our findings that the disruption of MF LTP maintenance by emetine is insensitive to MF intactness (Figs. $2 A, D$ ), it is tempting to speculate that protein synthesis required for MF LTP maintenance immediately after LTP induction occurs in postsynaptic elements.

In addition to protein synthesis, our results implicate RNA synthesis in the early maintenance of MF LTP. Actinomicyn-D produced a slower decay of the potentiated response than did emetine (Fig. 2 B; Table 1). These data are consistent with previous findings from other areas of the hippocampus indicating that levels of different RNAs generally are not increased until $\geq 30 \mathrm{~min}$ after HFS (Sadile et al., 1995; Morimoto et al., 1998; French et al., 2001; Steward and Worley, 2001).

\section{Importance of integrity of the presynaptic element in the} early maintenance of MF LTP

Our results show that transection of MF also produces a decay of MF LTP without affecting the amplitude of baseline responses or PTP. One possible mechanism responsible for this effect is the interruption of fast axonal transport of proteins associated with synaptic vesicles and neurotransmitter metabolism from the granule cell soma to the MF bouton. If we assume a fast anterograde transport rate of $200-400 \mathrm{~mm} / \mathrm{d}$ (Brown, 2000) and an average distance of $1010 \pm 43 \mu \mathrm{m}(n=3)$ between the gyrus dentate and the site of our recordings in area CA3, then it is plausible that by the time the slices are transferred to the recording chamber after $2 \mathrm{hr}$ of incubation, the MF boutons are depleted of the proteins required for the maintenance of LTP. Our data also show that in contrast to LTP induced by HFS, MF transection did not affect the maintenance of long-lasting potentiation induced by forskolin/IBMX. It has been postulated that the increase in cAMP levels caused by forskolin/IBMX induces a long-lasting MF potentiation through presynaptic mechanisms that result in enhancement of glutamate release (Lonart and Südhof, 1998; Villacres et al., 1998) attributable to an increase in phosphorylation of rabphilin (Rab3A) (Castillo et al., 1997, 2002). One possible explanation for this difference in the actions of MF transection is that interruption of the fast axonal transport affects biochemical steps upstream to cAMP production in the MF bouton. Our data strengthen the idea that the presynaptic element, granule cell soma and bouton, plays a critical role in the maintenance of MF LTP (Lonart, 2002). However, our observations that inhibition of protein synthesis affects forskolin/IBMXinduced MF potentiation and has the same effect on MF LTP when MF axons are intact as when MF axons are transected suggest that the postsynaptic element contributes to MF LTP maintenance as well. It is feasible that postsynaptic processes contribute to MF LTP immediately after its induction, whereas presynaptic mechanisms come on line somewhat later. Our observations that MF LTP also is disrupted by protein synthesis inhibitors when these agents are applied $1 \mathrm{hr}$ after LTP induction suggests that MF LTP, in contrast to C/A LTP, requires persistent protein synthesis. It is an open question whether obligatory protein synthesis at later times after LTP induction occurs presynaptically or postsynaptically. In conclusion, our data indicate that the mechanisms required for the early maintenance phase of MF LTP include synthesis of new proteins and RNAs as well as signaling from presynaptic cell bodies. Whether signaling from presynaptic cell bodies is requisite for the necessary transcriptional events remains to be determined.

\section{References}

Aakalu G, Smith WB, Nguyen N, Jiang C, Schuman EM (2001) Dynamic visualization of local protein synthesis in hippocampal neurons. Neuron 30:489-502.

Barea-Rodríguez EJ, Rivera DT, Jaffe DB, Martínez Jr JL (2000) Protein synthesis inhibition blocks the induction of mossy fiber long-term potentiation in vivo. J Neurosci 20:8528-8532.

Bennet MR (2000) The concept of long term potentiation of transmission at synapse. Prog Neurobiol 60:109-137.

Brown A (2000) Slow axonal transport: stop and go traffic in the axon. Nat Rev Mol Cell Biol 1:153-156.

Castillo EP, Janz R, Südhof TC, Tzounopoulos T, Malenka RC, Nicoll RA (1997) Rab3A is essential for mossy fibre long-term potentiation in the hippocampus. Nature 388:590-593.

Castillo PE, Schoch S, Schmitz F, Südhof TC, Malenka RC (2002) R1M1 $\alpha$ is required for presynaptic long-term potentiation. Nature 415:327-330.

Chicurel ME, Terrian DM, Potter H (1993) mRNA at the synapse: analysis 
of a synaptosomal preparation enriched in hippocampus dendritic spines. J Neurosci 13:4054-4063.

Clayton DF (2000) The genomic action potential. Neurobiol Learn Mem $74: 185-216$.

Contractor A, Rogers C, Maron C, Henkemeyer M, Swanson G, Heinemann SF (2002) Trans-synaptic Eph receptor-epherin signaling in hippocampal mossy fiber LTP. Science 296:1864-1869.

Davis S, Salin H, Helme-Guizon A, Dumas S, Stéphan A, Corbex M, Mallet J, Laroche S (2000) Dysfunctional regulation of $\alpha$ CaMKII and syntaxin $1 \mathrm{~B}$ transcription after induction LTP in the aged rat. Eur J Neurosci 12:3276-3282.

Deadwyler SA, Dunwiddie T, Lynch G (1987) A critical level of protein synthesis is required for long-term potentiation. Synapse 1:90-95.

French PJ, O'Connor V, Jones MW, Davis S, Errington ML, Voss K, Truchet B, Wotjak C, Stean T, Doyére V, Maroun M, Laroche S, Bliss TVP (2001) Subfield-specific immediate early gene expression associated with hippocampal long-term potentiation in vivo. Eur J Neurosci 13:968-976.

Frey U, Krug M, Reymann KG, Matthies H (1988) Anisomycin, an inhibitor of protein synthesis, blocks late phases of LTP phenomena in the hippocampal CA1 region. Brain Res 452:57-65.

Frey U, Huang YY, Kandel E (1993) Effects of cAMP simulate a late stage of LTP in hippocampal CA1 neurons. Science 260:1661-1664.

Harris EW, Cotman CW (1986) Long-term potentiation of guinea pig mossy fiber responses is not blocked by $\mathrm{N}$-methyl-D-aspartate antagonists. Neurosci Lett 70:132-137.

Hicks A, Davis S, Rodger J, Helme-Guizon A, Laroche S, Mallet J (1997) Synapsin 1 and syntaxin 1B: key elements in the control of neurotransmitter release are regulated by neuronal activation and long term potentiation. Neuroscience 79:329-340.

Huang YY, Kandel ER (1996) Modulation of both the early and the late phase of mossy fiber LTP by the activation of $\beta$-adrenergic receptors. Neuron 16:611-617.

Huang YY, Li XC, Kandel ER (1994) cAPM contributes to mossy fibers LTP by initiating both a covalently mediated early phase and macromolecular synthesis-dependent late phase. Cell 79:69-79.

Huang YY, Nguyen P, Abel T, Kandel E (1996) Long-lasting forms of synaptic potentiation in the mammalian hippocampus. Learn Mem 3:74-85.

Job C, Eberwine J (2001) Localization and translation of mRNA in dendrites and axons. Nat Rev 2:889-898.

Kacharmina JE, Job C, Crino P, Eberwine J (2000) Stimulation of glutamate receptor protein synthesis and membrane insertion within isolated neural dendrites. Proc Natl Acad Sci USA 97:11545-11550.

Kim CH, Lisman JE (1999) A role of actin filament in synaptic transmission and long-term potentiation. J Neurosci 19:4314-4324.

Krucker T, Siggins GR, Halpain S (2000) Dynamic actin filaments are required for stable long-term potentiation (LTP) in area CAl of the hippocampus. Proc Natl Acad Sci USA 97:6856-6861.

Krug M, Lössner B, Ott T (1984) Anisomycin blocks the late phase of long term potentiation in the dentate gyrus of freely moving rats. Brain Res Bull 13:39-42.

Lanahan A, Worley P (1998) Immediated-early genes and synaptic function. Neurobiol Learn Mem 70:37-43.

Langdon RB, Johnson J, Barrionuevo G (1995) Posttetanic potentiation and presynaptically induced long-term potentiation at the mossy fiber synapse in rat hippocampus. J Neurobiol 26:370-385.

Lonart G (2002) RIM1: an edge for presynaptic plasticity. Trends Neurosci 25:329-332.

Lonart G, Südhof TC (1998) Region-specific phosphorylation of rabphilin in mossy fiber nerve terminals of the hippocampus. J Neurosci 18:634-640.

Lopez-Garcia JC (1998) Two different forms of long-term potentiation in the hippocampus. Neurobiology 6:75-98.

Lynch MA, Voss KL, Rodriguez J, Bliss TBP (1994) Increase in synaptic vesicles proteins accompanies long-term potentiation in the dentate gyrus. Neuroscience 60:1-5.

Lüscher A, Nicoll RA, Malenka RC, Muller D (2000) Synaptic plasticity and dynamic modulation of the postsynaptic membrane. Nat Neurosci 3:545-550.

Maeda T, Kaneko S, Akaike A, Satoh M (1997) Direct evidence for increase in excitatory amino acids release during mossy fiber LTP in rat hippocampal slices as revealed by the patch sensor methods. Neurosci Lett 224:103-106.
Malinow R, Malenka RC (2002) AMPA receptor trafficking and synaptic plasticity. Annu Rev Neurosci 25:103-126.

Mochida H, Sato K, Sasaki S, Yazawa I, Kamino K, Momose-Sato Y (2001) Effects of anisomycin on LTP in the hippocampal CA1: long term analysis using optical recording. NeuroReport 12:987-991.

Morimoto K, Sato K, Sato S, Yamada N, Hayabara T (1998) Timedependent changes in rat hippocampal synapsin I mRNA expression during long-term potentiation. Brain Res 783:57-62.

Nguyen PV, Kandel E (1996) A macromolecular synthesis-dependent late phase of long-term potentiation requiring cAMP in the medial perforant pathway of rat hippocampal slices. J Neurosci 16:3189-3198.

Nguyen PV, Abel T, Kandel E (1994) Requirement of a critical period of transcription for induction of a late phase of LTP. Science 265:1104-1107.

Osten P, Valsamis L, Harris A, Sacktor TC (1996) Protein synthesisdependent formation of protein kinase $\mathrm{M} \zeta$ in long term potentiation J Neurosci 16:2444-2451.

Otani S, Abraham WC (1989) Inhibition of protein synthesis in the dentate gyrus, but not the entorhinal cortex, blocks maintenance of long-term potentiation in rats. Neurosci Lett 106:175-180.

Otani S, Marshal CJ, Tate WP, Goddard GV, Abraham WC (1989) Maintenance of long-term potentiation in rat dentate gyrus requires proteins synthesis but not messenger RNA synthesis immediately posttetanization. Neuroscience 28:519-526.

Ouyang Y, Rosenstein A, Kreiman G, Schuman EM, Kennedy MB (1999) Tetanic stimulation leads to increased accumulation of $\mathrm{Ca}^{2+}$ / calmodulin-dependent protein kinase II via dendritic protein synthesis in hippocampus neurons. J Neurosci 19:7823-7833.

Sadile A, Neugebauer A, Gessi S, Marchionni S, Giudittas A (1995) Brain RNA synthesis, long-term potentiation and depression at the perforant path-granule cell synapse in the guinea pig. Brain Res Bull 36:515-526.

Sato K, Morimoto K, Suemaru S, Sato S, Yamada N (2000) Increased synpasin I immunoreactivity during long-term potentiation in rat hippocampus. Brain Res 872:219-222.

Scharf MT, Woo NH, Lattal M, Young JZ, Nguyen PV, Abel T (2002) Protein synthesis is required for the enhancement of long-term potentiation and long-term memory by spaced training. J Neurophysiol 87:2770-2777.

Smith WB, Aakalu G, Schuman EM (2001) Local protein synthesis in neurons. Curr Biol 11:R901-R903.

Son H, Carpenter DO (1996) Protein kinase C activation is necessary but not sufficient for induction of long-term potentiation at the synapse of mossy fiber-CA3 in the rat hippocampus. Neuroscience 72:1-13.

Stanton PK, Sarvey JM (1984) Blockade of long term potentiation in rat hippocampal CA1 region by inhibitors of protein synthesis. J Neurosci 4:3080-3088.

Steward O, Schuman EM (2001) Protein synthesis at synaptic sites on dendrites. Annu Rev Neurosci 24:299-325.

Steward O, Worley PF (2001) Selective targeting of newly synthetized Arc mRNA to active synapse requires NMDA receptor activation. Neuron 30:227-240.

Steward O, Worley PF (2002) Local synthesis of proteins at synaptic sites on dendrites: role in synaptic plasticity and memory consolidation? Neurobiol Learn Mem 78:508-527.

Urban NN, Barrionuevo G (1996) Induction of Hebbian and non-Hebbian mossy fiber long-term potentiation by distinct patterns of high-frequency stimulation. J Neurosci 16:4293-4299.

Villacres E, Wong S, Chavkin C, Storm D (1998) Type I adenylyl cyclase mutant mice have impaired mossy fiber long-term potentiation. J Neurosci 18:3186-3194.

Weisskopf MG, Nicoll RA (1995) Presynaptic changes during mossy fibre LTP revealed by NMDA receptor-mediated synaptic responses. Nature 376:256-259.

Weisskopf MG, Castillo PE, Zalutsky RA, Nicoll RA (1994) Mediation of hippocampal mossy fiber long-term potentiation by cyclic AMP. Science 265:1878-1882.

Xiang Z, Greenwood AC, Kairiss EW, Brown TH (1994) Quantal mechanism of long-term potentiation in hippocampal mossy-fiber synapses. J Neurophysiol 71:2552-2556.

Yamagata K, Andreasson KI, Sugiura H, Maru E, Dominique M, Irie Y, Miki N, Hayashi Y, Yoshioka M, Kaneko K, Kato H, Worley PF (1999) Arcadlin is a neural activity-regulated cadherin involved in long term potentiation. J Biol Chem 274:19473-19479. 